\title{
An Economic Instrument to Improve the Climate in Sweden
}

\author{
Jan Stenis \\ Kristianstad, Sweden \\ Email: jan.stenis@icloud.com
}

How to cite this paper: Stenis, J. (2020). An Economic Instrument to Improve the Climate in Sweden. Theoretical Economics Letters, 10, 758-769.

https://doi.org/10.4236/tel.2020.104047

Received: April 26, 2020

Accepted: August 2, 2020

Published: August 5, 2020

Copyright $\odot 2020$ by author(s) and Scientific Research Publishing Inc. This work is licensed under the Creative Commons Attribution International License (CC BY 4.0).

http://creativecommons.org/licenses/by/4.0/

(c) (i) Open Access

\begin{abstract}
Objectives: The Naturally Optimised Revenue Demand in Communities (NORDIC) model was applied to improve the Swedish climate. When substantial changes in the atmosphere's temperature occur, the profits can be reduced, creating a strong driving force for authorities to cope with climate change. A new and practical economic instrument was introduced to improve climate management, based on the NORDIC model. Methods: Constructed shadow costs were produced to be inserted into the public accounts. This procedure induced economic incentives to decrease the climate changes. The launched methodology considered the public awareness about climate change issues. This case study provided an example of how to improve the climate in the Swedish society by applying the NORDIC model. Results: The methodology could improve the climate and decrease its fluctuations by using economic instruments. The resulting shadow cost impacted the Public Sector Borrowing Requirement. An introduced key factor expressed, by one digit only, the success of the climate policy. Conclusions: The NORDIC model could improve the Swedish climate and its danger to health. Governments obtain a tool to monitor, manage and evaluate the atmosphere. End users include environmental authorities and politicians that want a climate policy tool. The NORDIC model is recommended to apply to climate issues and raise the public awareness about climate change. Further research focus on algorithms for certain climates and affected citizens.
\end{abstract}

\section{Keywords}

Climate Change, Economic Instrument, Sweden

\section{Introduction}

Excessive, volatile weather is a global problem with huge, economic conse- 
quences. Between 1999 and 2018, about 495,000 people died worldwide and losses of USD3.54 trillion (in purchasing power parities) were incurred as a direct result of more than 12,000 extreme weather events (Eckstein et al., 2019). Climate change mitigation consists of actions to limit the magnitude or rate of global warming and its related effects. Climate change mitigation generally involves reductions in anthropogenic emissions of greenhouse gases (GHGs). Mitigation may also be achieved by increasing the capacity of carbon sinks, for example through reforestation (Climate Change Mitigation, 2020).

This article considers the nations' climate change-burden. The objective was to provide a new decision-support tool for authorities, politicians and other citizens interested in climate policy. This effort was based on the Naturally Optimised Revenue Demand in Communities, NORDIC model (Stenis, 2020a, 2020b, 2020c; Stenis \& Hogland, 2019). The main goal was to make the use of the NORDIC model easier for environmental authorities and climate managers. The hypothesis was that the climate could be improved by applying the NORDIC model. The research question was whether the climate could be improved by using economic instruments.

The research aimed at accomplishing a change. The method was case studies of stakeholders. An analytical approach was used. The research design highlighted a logical approach. That supported the logic which was embedded in the mathematics of the NORDIC model and backed up by relevant data. Thus, a quantitative research methodology dominated. The implication of the study was an improved scientific background to make decisions. The launched tool increased the theoretical knowledge.

The case studies give an example of how the Swedish climate can be improved. Know-how was accumulated. The practical results of this study were better opportunities for leaders to, based on logics, explain their reasons for actions. The filled research gap was innovative, economic instruments to manage climate change. The work improved the economy, which improved the living conditions.

\section{Literature Review}

Works by other academics and scholars on climate change, climate change mitigation, economic instruments, shadow costs and models were reviewed. The review showed that Ruiz-Benito et al. (2020) identified major climate change impacts. Steinberg et al. (2020) showed that the impacts of climate change can be understood with greater certainty at the national level than at the regional level.

Ji and Ranjan (2019) developed an integrated global climate-economy assessment model of carbon mitigation. Kopra (2019) explored how China's rise to great power status transforms notions of responsibility in international climate politics in particular. Mechler (Ed.) et al. (2019) provided insight on the Loss and Damage discourse, because climate mitigation and adaptation may not be enough to manage the effects from anthropogenic climate change. Nordhaus 
(2019) addressed the climate-change externality; its sources, its potential impacts, and the policy tools that are available to stem the rising tides and damages. Rondeau-Genesse and Braun (2019) used CanESM2-LE and CESM-LE, two state-of-the-art large ensembles (LE), indicating that under the RCP8.5, temperatures will increase in a roughly linear manner between 2021 and 2060. Sun et al. (2019) used six state-of-the-art energy-economy analysis models and four long term scenarios to explore regional contributions for climate change mitigation. Teske (Ed.) (2019) presented pathways to achieve the climate mitigation targets set out in the Paris Climate Agreement.

Füssel et al. (2018) provided the first systematic review of national climate change impact, vulnerability and risk (CCIV) assessments for countries that will support the adaptation to climate change in Europe. Jordan (Ed.) (2018) provided the first systematic test of the ability of polycentric thinking to explain and enhance societal attempts to govern climate change. Klepp and Chavez-Rodriguez (Eds.) (2018) gave examples from countries to describe how adaptation measures are interpreted, transformed, and implemented at grassroots level. Kravtsov and Grimm (2018) showed that none of the model simulations considered matched the observed signal, highlighting a substantial degree of uncertainty in the observed climate change. Ring et al. (2018) evaluated global circulation models and regional climate models and revealed that trend results are suitable for assigning weighting factors to climate models. Zommers \& Alverson (Eds.) (2018) assessed the need to provide tools and methods used in adaptation to climate change. Hwang (2017) developed a recursive method that produced exact solutions to a simple economic growth model and is useful for solving more demanding models, such as the Dynamic Integrated Model of Climate and the Economy (DICE) model. Kolstad et al. (2014) contributed to the Fifth Assessment Report of the Intergovernmental Panel on Climate Change by defining economic instruments (EIs) as including incentives that alter the conditions or behavior of target participants, lead to a reduction in aggregate emissions and tend to be more cost-effective than regulatory interventions. Akhtar et al. (2013) outlined the ANEMI_2 model to evaluate market and nonmarket costs and benefits of climate change. Kotchen, Boyle and Leiserowitz (2013) provided the first willingness-to-pay (WTP) estimates and found that the WTP does not vary substantially among the policy instruments of a cap-and-trade program, a carbon tax, or a GHG regulation. Meckling \& Hepburn (2013) explored the economics of instruments and examined the history and politics of instrument choice.

Chou, Dong \& Feng (2010) conducted an interdisciplinary investigation using an economy-climate model (C-D-C), suggesting that the $\mathrm{C}-\mathrm{D}-\mathrm{C}$ models are superior to the classic C-D model. Hahn (2009) reviewed the economics and politics of climate change when the Kyoto period to 2012 came to an end and examined the incentives of the US, EU and China and the policies governments can put in place to reduce greenhouse gas emissions. Lagarde (2008) demonstrated how economic instruments can fight the economic issue of climate 
change because climate change could lead to a sharp drop in GDP in all economies. Nordhaus (2000) presented the RICE-99 (Regional Dynamic Integrated model of Climate and the Economy) and DICE-99 (Dynamic Integrated Model of Climate and the Economy) to enable better design of economic and environmental policies.

This study considers these, and other, aspects of climate policy due to that currency is used to encompass factors of importance for atmosphere management. No approaches similar to the NORDIC model exist that, by a single key factor, simultaneously improve the climate and take the public awareness of climate change into account.

\section{Research Methods}

The NORDIC model (Stenis, 2020a, 2020b, 2020c; Stenis \& Hogland, 2019) was the basis for this work. The NORDIC model was adapted to climate issues with emphasis on climate change mitigation.

\subsection{The Subjects}

The methodology was tested on the climate in Sweden in a realistic case study. Sweden was chosen because this nation has a long tradition of powerful environmental authorities that provide plenty of relevant data.

\subsection{The Study Procedures}

\subsubsection{Experimental Interventions}

Personal computers were used. Thus, no direct intervention took place.

\subsubsection{Sampling Procedures, Sample Size} and Ethical Considerations

Recent and reliable data were obtained from public internet sources. No agreements or payments were made. The sample size was the climate in the nation of Sweden. No living individuals or animals were directly involved. The study required no physical safety precautions.

\subsubsection{Measurement Approaches}

Observations of relevant study-groups via online sources were made. Only reliable sources on the internet were consulted. Usage of impersonal, socio-economic data granted the cultural validity.

\subsubsection{The Research Design}

The scientific background and reasons for performing the study is given in the introduction. The mathematics for the NORDIC model, and a description of how to use it for climate change mitigation purposes, is provided. A case study gives an example of how the Swedish climate can be improved. This is followed by the results and discussion, conclusion, benefits of the model, and recommendations for users of the model. 


\subsection{Theory Foundation}

The NORDIC model produces a shadow cost (Shadow Price, 2020) that shows the performance of the study object.

$$
S=\left(\frac{X}{Y}\right) \sum Z * W=\left(\left(\sum V-\sum C\right) / Y\right) * \sum Z * W
$$

where, $S$ is the Shadow cost to be additionally inserted in the accounts of the organization; $X$ is the net worth of the phenomenon to be optimized. $X=V-$ $C$ ( $V$ is the Value of $X ; C$ is the Cost of $X$ ); $Y$ is the total value of the organization; $Z$ is the value of the entities connected to $X ; W$ is the Weight factor for the general impact of $X$ on society, during a certain period in a certain, administrative unit.

USD, kilogram, liter or Joule can be applied as sorts. The $W$ factor is a decimal number, it has no sort.

\subsection{Application of the NORDIC Model to Climate Change}

Economic considerations are featured concerning the climate. The Nordic model produces a constructed shadow cost that points at how well the climate is improved.

$$
\begin{gathered}
S_{\text {climate }}=((V-C) / G) * D * B \\
0<B<100 \text { percent } / 100
\end{gathered}
$$

where, $S_{\text {climate }}$ is the Shadow cost for climate changes; $V$ is the Value of an increased content of carbon in the atmosphere; $C$ is the Cost for an increased content of carbon in the atmosphere; $G$ is the Gross Domestic Product (GDP); $D$ is the costs for climate-related Disasters such as hurricanes, fires and flooding, and; $B$ is the citizens' Belief in climate changes due to anthropogenic impact, without sort, it is a decimal number. Period: annually. Sort: US dollars.

Table 1 shows how to use the shadow cost $S_{\text {climate }}$ in practice (Ekonomifakta, 2020a). Here, the shadow cost $S_{\text {climate }}$ is added to the expenses of a certain nation, because the parameter $D$ is a cost that has a negative impact.

In general, a reduced Public Sector Borrowing Requirement (PSBR) due to a decreasing $S_{\text {climate }}$ cost announces a more successful atmosphere management than previously. An increased $S_{\text {climate }}$ cost that raises PSBR calls for an improved climate policy.

Note that the NORDIC model does not tell managers which means and measures to implement. It just indicates the climate-status, to provide a decision-basis for how powerful tools to employ, without saying precisely which.

Table 1. The nation's public budget.

\begin{tabular}{c}
\hline Revenues \\
\hline Expenses $S_{\text {climate }}$ \\
Public Sector Borrowing Requirement \\
\hline
\end{tabular}




\subsection{Analysis}

If the PSBR decreases when the $S_{\text {climate }}$ goes down, the climate policy has become more successful. If the PSBR increases when the $S_{\text {climatee }}$ goes up, this tells climate authorities to act, but it does not decide by which action.

\subsection{Manual for Practical Application of the NORDIC Model to Climate Change}

Use the following steps when the NORDIC model is applied to climate change issues.

1) Estimate the parameter values in Equation (2).

2) Calculate the shadow cost $S_{\text {climate }}$.

3) Re-estimate the parameters in Equation (2).

4) Re-calculate $S_{\text {climate }}$ to follow its development.

5) Take improving actions if $S_{\text {climate }}$ increases.

Relevant authorities that use the NORDIC model are supposed to collaborate. In doing so, the climate and the public awareness can be improved where the NORDIC model is applied.

\subsection{Case Study: Application of the NORDIC Model to Swedish Climate in 2018}

$X$ given by the Swedish, national costs for climate adaption was USD21 million (SEK214 million) (Swedish Government, 2017).

$G$ by the Swedish GDP was USD483 billion (SEK4834 billion) (Statistics Sweden, 2020).

$D$ by the Swedish carbon tax was USD2.3 billion (SEK23 billion) (Ekonomifakta, 2020b).

$B$ by the Swedes' Belief in climate changes, due to anthropogenic impact, was 92\% (Climate Change Denial, 2020).

In this case study, an exchange rate of USD1 = SEK10 (April 2020) was used. Equations (2) and (3) give:

$$
S_{\text {climate }}=\left(\frac{\text { USD21 million }}{\text { USD483 billion }}\right) * \text { USD2.3 billion } * 0.92=\text { USD92 thousand }
$$

$S_{\text {climate }}=$ was added to the public budget of Sweden. Table 2 shows the impact on Sweden's public finances. $S_{\text {climate }}$ is a cost and hence inserted in the table as an expense.

An increased PSBR by about USD100 thousand forced the Swedish authorities to improve their climate policy. If the following estimations of $S_{\text {climate }}$ produced a

Table 2. The public budget of Sweden considering the shadow cost $\mathrm{S}$ of climate change.

\begin{tabular}{c}
\hline Revenues \\
Expenses $S_{\text {climate }}=$ kUSD92 \\
PSBR $+S_{\text {climate }}=$ PSBR + kUSD92 \\
\hline
\end{tabular}


lower shadow cost, Sweden had become better at mitigating the climate change. The very methods to hamper the climate change, were not provided by the NORDIC model.

\subsection{Sensitivity Analysis of the Introduced Theory}

Figure 1 shows the variation of the shadow cost $S$ when the main parameter $D$ varies. On the abscissa, variables around $D$ that are USD2.3 billion in Equation (4) are shown. The ordinate displays the results by Equation (4) for values of $D$ around USD2.3 billion. A constant slope of the graph gives a linear relationship. Therefore, the introduced theory gives a stable outcome for all inputs.

\section{Results and Discussion}

The objective of this article was to provide a new decision-support tool for authorities, politicians and other citizens interested in climate policy. The literature review showed that this was accomplished because a decision-support tool has been provided that these groups use. The Disaster factor $D$ in Equation (2) was employed with success in case studies concerning the climate change of Sweden. The Belief-factor B promoted health due to the shadow cost $S_{\text {climate }}$ increasing with a more concerned population. Table 1 illustrated the related increase in PSBR, hence improving awareness about the climate change effects.

The main goal was to make the use of the NORDIC model easier for environmental authorities and climate managers. This goal was accomplished by the successful adaptation of the NORDIC model to climate issues. This statement is supported by the authenticity of the case study. The hypothesis of this work was that the climate could be improved by applying the NORDIC model. This was proven by the logical mathematics and fidelity of the case study. The case studies produced realistic results. The research question to be answered was if the climate

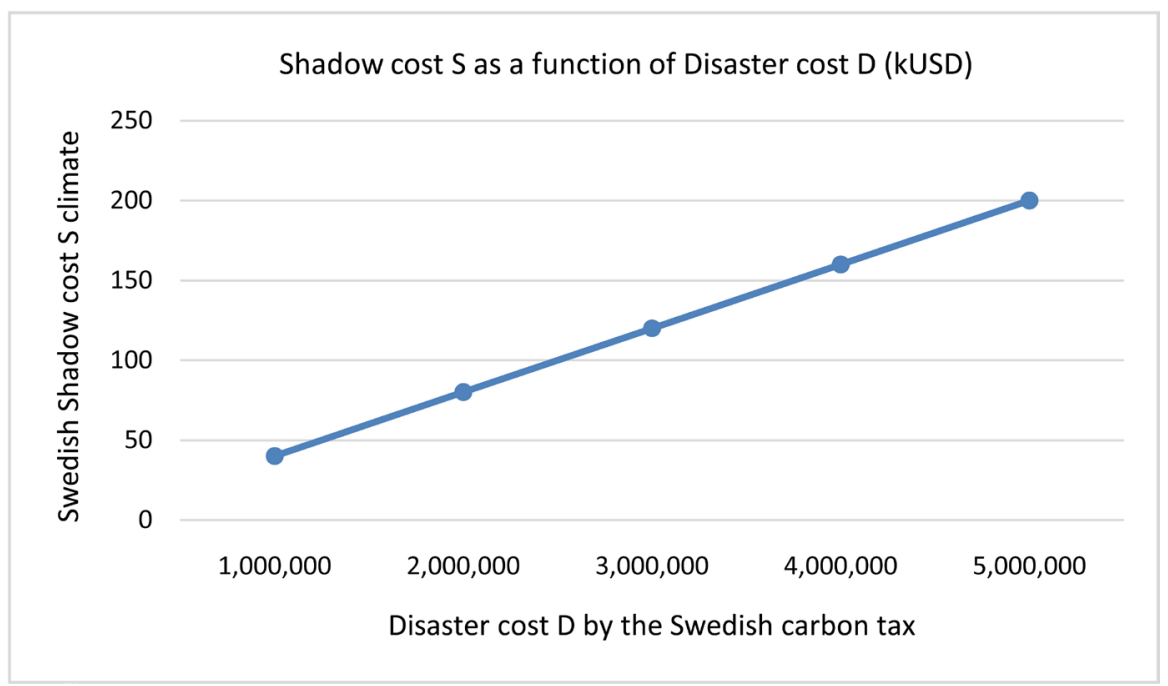

Figure 1. Relationship between the shadow cost $S$ and the disaster cost $D$ when applying the NORDIC model. 
could be improved by employing economic instruments? The answer is yes due to the developed equations' usefulness and the applicability of the shadow cost-approach to the environmental sector.

The case study resulted in a modest shadow cost of USD92 thousand. This points at the practical utility of the methodology. Therefore, the objective to give environmental authorities a new tool was met, particularly so since the model considers financial aspects and inhabitants' quality of life.

Over time, the development of a nation's atmosphere can be studied by politicians and other concerned parties. The economy and welfare enhance and human suffering is reduced.

The NORDIC model provides managers with a general picture of the situation but does not determine precisely which solutions to implement. Economic instruments work like that. A practical manual is included in the NORDIC model. The manual is presented in section 3.6.

The model does not pinpoint relevant sub-groups. This is a disadvantage because all categories affected by climate change become an anonymous mass in the launched equations. Thus, further research preferably focuses on algorithms for certain types of climate and groups of citizens affected by the application of the model, with emphasis on the relationship between the microclimate over larger cities and their impact on the surroundings.

The data were analyzed by the usage of numerical values in the developed equations. Equation (2) mirrors the reality intended to be influenced. The methods are robust and provide insights into the data. Analyses for statistical errors are not performed in this study that uses basic and easily available data. Interventions did not take place. The objects of interest were approached in an impersonal way and not directly affected during the work.

The reliability of this study is demonstrated by the correct calculations and the realistic case studies. The use of common economic theory illustrates the study's validity.

\section{Conclusion}

The NORDIC model could improve the climate in a nation. The presented model enhances the public awareness and improves welfare because the shadow cost $\left(S_{\text {climate }}\right)$ and the PSBR increase when the population's raised belief in climate changes, due to anthropogenic impact, results in an increased shadow cost $\left(S_{\text {cli- }}\right.$ mate) and PSBR. The result is authorities taking stronger actions when the public awareness improves.

This work provides novel solutions to promote a stable climate and citizens' wellbeing, thereby contributing to the literature. The environmental authorities' performance is improved by making the decision process more efficient. These improved management practices are the study's main contribution to scientific knowledge. The findings impact both the private and public environmental sectors.

The main finding was that the NORDIC model constituted a versatile theory 
to improve the climate in nations, which experienced reduced economic and social burdens. This statement is proven by the results of the case study that was based on reliable data from public sources. My approach was novel because it used shadow costs in an innovative way. Economic incentives were created to improve the climate.

A key indicator $\left(S_{\text {climate }}\right)$ was introduced to monitor important aspects of climate change. This was a highlight. Methods were invented to facilitate climate managers' policy decisions. The most interesting finding from this study was the climate-related Disasters D-factor in Equation (2). This was a key attributing factor of this work.

\subsection{Benefits}

1) Citizens' suffering is reduced due to improved climate in Sweden.

2) Authorities obtain a practical tool to mitigate the climate change.

3) Methods based on common economic and mathematic theories.

\subsection{Recommendation}

I recommend applying the NORDIC model to climate change issues and employing the NORDIC model to improve the climate, decrease its negative impacts on health and raise the public awareness of climate change.

\section{Funding}

This research received no specific grant from funding agencies in the public, commercial, or not-for-profit sectors.

\section{The Author's Contribution to the Present Study}

J Stenis-Concept idea, planning of the work, performance of the literature study, methodology design, NORDIC model development, all the research effort, all the writing of the paper.

\section{Conflicts of Interest}

The author declares no conflicts of interest regarding the publication of this paper.

\section{References}

(2020). Climate Change Denial. In Wikipedia, the Free Encyclopedia. (In Swedish) https://sv.wikipedia.org/wiki/Klimatskepticism

(2020). Climate Change Mitigation. In Wikipedia, the Free Encyclopedia. https://en.wikipedia.org/wiki/Climate_change_mitigation

(2020). Shadow Price. In Wikipedia, the Free Encyclopedia. https://en.wikipedia.org/wiki/Shadow_price

Akhtar, M. K., Wibe, J., Simonovic, S. P., \& Macgee, J. (2013). Integrated Assessment Model of Society-Biosphere-Climate-Economy-Energy System. Environmental Model- 
ling and Software, 49, 1-21. https://doi.org/10.1016/j.envsoft.2013.07.006

Chou, J., Dong, W., \& Feng, G. (2010). Application of an Economy-Climate Model to Assess the Impact of Climate Change. Advances in Atmospheric Sciences, 27, 957-965. https://doi.org/10.1007/s00376-009-8166-8

Eckstein, D., Künzel, V., Schäfer, L., \& Winges, M. (2019). Global Climate Risk Index 2020. Who Suffers Most from Extreme Weather Events? Weather-Related Loss Events in 2018 and 1999 to 2018. Bonn: Germanwatch.

https://germanwatch.org/sites/germanwatch.org/files/20-2-01e\%20Global\%20Climate \%20Risk\%20Index\%202020_10.pdf

Ekonomifakta (2020a). The Nation's Public Budget. (In Swedish)

https://www.ekonomifakta.se

Ekonomifakta (2020b). Energy Taxes and Ecotax. (In Swedish) https://www.ekonomifakta.se/Fakta/Energi/Styrmedel/Energi-och-miljoskatter

Füssel, H.-M., Lourenço, T. C., Downing, C., Hildén, M., Leitner, M., Marx, A., Prutsch, A., \& Sanderson, M. (2018). National Climate Change Vulnerability and Risk Assessments in Europe, 2018. EEA Report No. 1/2018, Luxembourg: Publications Office.

Hahn, R. W. (2009). The Economics and Politics of Climate Change. Oxford: Oxford University Press.

Hwang, I. C. (2017). A Recursive Method for Solving a Climate-Economy Model: Value Function Iterations with Logarithmic Approximations. Computational Economics, 50, 95-110. https://doi.org/10.1007/s10614-016-9583-2

Ji, Y., \& Ranjan, R. (2019). A Global Climate-Economy Model Including the REDD Option. Journal of Environmental Management, 247, 342-355. https://doi.org/10.1016/j.jenvman.2019.06.052

Jordan, A. (2018). Governing Climate Change: Polycentricity in Action? Cambridge: Cambridge University Press. https://doi.org/10.1017/9781108284646

Klepp, S., \& Chavez-Rodriguez, L. (2018). A Critical Approach to Climate Change Adaptation: Discourses, Policies, and Practices. New York: Routledge. https://doi.org/10.4324/9781315165448

Kolstad C., Urama, K., Broome, J., Bruvoll, A., Carino Olvera, M., Fullerton, D., Gollier, C., Hanemann, W. M., Hassan, R., Jotzo, F., Khan, M. R., Meyer, L., \& Mundaca, L. (2014). Social, Economic and Ethical Concepts and Methods. In O. Edenhofer, R. Pichs-Madruga, Y. Sokona, E. Farahani, S. Kadner, K. Seyboth, A. Adler, I. Baum, S. Brunner, P. Eickemeier, B. Kriemann, J. Savolainen, S. Schlömer, C. von Stechow, T. Zwickel, \& J. C. Minx (Eds.), Climate Change 2014: Mitigation of Climate Change. Contribution of Working Group III to the Fifth Assessment Report of the Intergovernmental Panel on Climate Change (pp. 207-282). Cambridge: Cambridge University Press. https://www.ipcc.ch/site/assets/uploads/2018/02/ipcc_wg3_ar5_chapter3.pdf

Kopra, S. (2019). China and Great Power Responsibility for Climate Change. London: Routledge. https://doi.org/10.4324/9781315151113

Kotchen, M., Boyle, K., \& Leiserowitz, A. (2013). Willingness-to-Pay and Policy-Instrument Choice for Climate-Change Policy in the United States. Energy Policy, 55, 617-625. https://doi.org/10.1016/j.enpol.2012.12.058

Kravtsov, S., \& Grimm, C. (2018). Global-Scale Multidecadal Variability Missing in State-of-the-Art Climate Models. NPJ Climate and Atmospheric Science, 1, 34. https://doi.org/10.1038/s41612-018-0044-6

Lagarde, C. (2008). Economic Instruments in the Fight against Climate Change. (LEADERS). OECD Observer, 267, 4-5. 
Mechler, R., Bouwer, L. M., Schinko, T., Surminsky, S., \& Linnerooth-Bayer, J. (2019). Loss and Damage from Climate Change: Concepts, Methods and Policy Options. Cham: Springer. https://doi.org/10.1007/978-3-319-72026-5

Meckling, J., \& Hepburn, C. (2013). Economic Instruments for Climate Change. In R. Falkner (Ed.), The Handbook of Global Climate and Environment Policy (Chapter 27). Chichester: Wiley-Blackwell. https://doi.org/10.1002/9781118326213.ch27

Nordhaus, W. (2019). Climate Change: The Ultimate Challenge for Economics. The American Economic Review, 109, 1991-2014. https://doi.org/10.1257/aer.109.6.1991

Nordhaus, W. D. (2000). Warming the World: Economic Models of Global Warming. Cambridge, MA: MIT Press. https://doi.org/10.7551/mitpress/7158.001.0001

Ring, C., Polinger, F., Kaspar-Ott, I., Hertig, E., Jacobeit, J., \& Paeth, H. (2018). A Comparison of Metrics for Assessing State-of-the-Art Climate Models and Implications for Probabilistic Projections of Climate Change. Climate Dynamics, 50, 2087-2106. https://doi.org/10.1007/s00382-017-3737-3

Rondeau-Genesse, G., \& Braun, M. (2019). Impact of Internal Variability on Climate Change for the Upcoming Decades: Analysis of the CanESM2-LE and CESM-LE Large Ensembles. Climatic Change, 156, 299-314.

https://doi.org/10.1007/s10584-019-02550-2

Ruiz-Benito, P., Vacchiano, G., Lines, E. R., Reyer, C. P. O., Ratcliffe, S., Morin, X., Hartig, F., Mäkelä, A., Yousefpour, R., Chaves, J. E., Palacios-Orueta, A., Benito-Garzón, M., Morales-Molino, C., Camarero, J. J., Jump, A. S., Kattge, J., Lehtonen, A., Ibrom, A., \& Zavala, M. A. (2020). Available and Missing Data to Model Impact of Climate Change on European Forests. Ecological Modelling, 416, 1-15.

https://doi.org/10.1016/j.ecolmodel.2019.108870

Statistics Sweden (2020). Sweden's GDP. (In Swedish) https://www.scb.se/hitta-statistik/sverige-i-siffror/samhallets-ekonomi/bnp-i-sverige

Steinberg, D., Mignone, B., Macknick, J., Sun, Y., Eurek, K., Badger, A., Livneh, B., \& Averyt, K. (2020). Decomposing Supply-Side and Demand-Side Impacts of Climate Change on the US Electricity System through 2050. Climatic Change, 158, 125-139. https://doi.org/10.1007/s10584-019-02506-6

Stenis, J. (2020a). An Economic Instrument to Improve Migration. Applied Economics and Finance, 7, 15-20. https://doi.org/10.11114/aef.v7i1.4630

Stenis, J. (2020b). Application of the Naturally Optimised Revenue Demand in Communities NORDIC Model to Improve the Workforce in Sweden. Applied Economics and Finance, 7, 18-23. https://doi.org/10.11114/aef.v7i2.4711

Stenis, J. (2020c). Application of the Naturally Optimised Revenue Demand in Communities NORDIC Model to Improve the Education in Sweden. Theoretical Economics Letters, 10, 523-534. https://doi.org/10.4236/tel.2020.103033

Stenis, J., \& Hogland, W. (2019). An Economic Instrument to Improve Communities. Theoretical Economics Letters, 9, 1804-1816. https://doi.org/10.4236/tel.2019.96115

Sun, H., Niu, S., \& Wang, X. (2019). Future Regional Contributions for Climate Change Mitigation: Insights from Energy Investment Gap and Policy Cost. Sustainability, 11, 3341. https://doi.org/10.3390/su11123341

Swedish Government (2017). General Environmental Care and Nature Conservation, Suggestions for the National Budget 2018, Government Bill 2017/18:1, Expenditure Area 20. (In Swedish)

https://www.regeringen.se/4a65cf/contentassets/79f6d27416794fobb146c792e02b65fc/u tgiftsomrade-20-allman-miljo-och-naturvard.pdf 
Teske, S. (2019). Achieving the Paris Climate Agreement Goals: Global and Regional 100\% Renewable Energy Scenarios with Non-Energy GHG Pathways for $+1.5^{\circ} \mathrm{C}$ and $+2^{\circ}$ C. Cham: Springer. https://doi.org/10.1007/978-3-030-05843-2

Zommers, Z., \& Alverson, K. D. (2018). Resilience: The Science of Adaptation to Climate Change. Amsterdam: Elsevier. https://doi.org/10.1177/0739456X20916512 